\title{
Design and Realization of Multi-Material and Multi-Process Deposition Method
}

\author{
Valerio Giuliani, T. Freiheit, Peihua Gu \\ Department of Mechanical and Manufacturing Engineering \\ University of Calgary \\ 2500 University Drive NW, Calgary, Alberta, T2N 1N4 \\ giuliani@enme.ucalgary.ca
}

\begin{abstract}
Traditional rapid prototyping $(R P)$ technologies have been widely used to create freeform prototypes ready to work as functional objects. Although RP technologies are flexible for making free-form objects, each RP technology can only produce very limited products as only certain materials are allowed. In order to manufacture a wider range of components a new RP method called MMMPDM (Multi Material and Multi Process Deposition Method) is being implemented. The system is capable of using more than one material to produce parts with specific requirements that cannot be met by a single material, such as with graded composition and locally controlled properties. This paper reports on the design and realization of a Multi Materials and Multi Processes Deposition Machine.
\end{abstract}

\section{Introduction}

Rapid prototyping technologies [1] have been widely used in the past two decades. Many RP techniques have been developed and implemented in order to create a large variety of prototypes. Three dimensional objects are built with polymers, metals or ceramics using well known traditional RP processes or the most recent RP trends. Although some of these processes are capable of generating components with the same material, they can be classified by their material supply system. A few examples are Fused Deposition Modeling (FDM) [2][3] below,Stereo Lithography (SLA) [4][5][6], and Selecting Laser Sintering (SLS) [7][8][9]. FDM uses polymer wires that through a heated nozzle are deposited on the working base in a semi molten state. SLA creates its prototypes by scanning and curing the surface of a liquid polymer layer by layer. Using the same concept, SLS creates prototypes by scanning and sintering thin layers of material powder. All three methods use a control system that drives the deposition, curing, or sintering process according to CAD files loaded into the system.
Recently researchers have developed deposition techniques, such as Laser Engineering Net Shaping (LENS) [10][11], based on cladding [12] technologies. Cladding is a surface process which changes the material properties at the surface of a component by adding a layer of different material. Surface cladding has been widely investigated in the material processing literature and cladding application for rapid prototyping purposes is becoming a trend. For RP, LENS is a technology that builds fully dense prototypes by spraying metal powder into the melting pool of a high power Nd-Yag laser beam. When the laser moves, a thin line of solid metal is left behind and the building process carries on layer by layer. Many other recent techniques have been implemented based on the LENS concept and all of them have advantages and disadvantages as stated in the literature.

The objective of the paper is to show the limitation of the existing RP technologies and to outline a unique solution that allows the integration of $\mathrm{RP}$ processes in a single machine in order to achieve a more flexible solution for material deposition and processing. The paper starts by outlining the limitations of the existing rapid prototyping technologies and focus on their major design needs. Section 3 describes the design requirements that meet those needs. The paper proceeds with a functional design decomposition and shows the principal solution to the design requirements. A detailed design of the MMMPDM machine is proposed at this early stage of design and the paper ends with conclusion and future work.

\section{Limitations of Current Technologies}

Traditional RP techniques are still an active instrument in the world of manufacturing. Although they are capable of creating complex geometries, they are still limited in their use as final products. Prototypes are not always functional due to the model material used, and the material is still connected to the use of a specific RP technique. If we need an ABS 
prototype we would probably use an FDM machine, and if a metal component is required, SLS or LENS are the best candidates

The main restriction of the traditional RP processes is the inability of building objects with more than one material using the same machine. Only recently has LENS technology investigated the use of a second material [16] below. In addition, existing commercial machines are specialized only in building prototype, and they are not capable of performing different actions such as surface processing.

Another important limitation is represented by the use of a single power source for material deposition. It is acknowledged that different energy sources can be more efficient than others when processing different materials; for example an electric arc can melt aluminium easier than a laser beam.

In conclusion we can classify these limitations as follows:

1. Single material Prototypes

2. Single Energy source

3. Limited position and motion control

4. Prototype not always functional
These four points represent the starting point for the flow of information that characterizes the design process. The current RP limitations are the starting point in the determination of the design needs, Figure 1. Needs can be divided into two main categories: Multi Material and Integration.

Multi Material represents the capability of the RP system for changing its material in its sub systems, if a variety is in fact needed:

1. "Within the Prototype" -when different materials can be simultaneously processed during the building phase in order to create objects with multiple properties (e.g. Mechanical, Electrical, Magnetic).

2. "For different Prototypes" -when prototypes can be built in a variety of material on demand, with no delay and without changing the RP machine.

Integration is the possibility of integrating more than one process, whether it be RP or not, in a single machine. We believe that integrating multiple processes will increase the flexibility of the system for

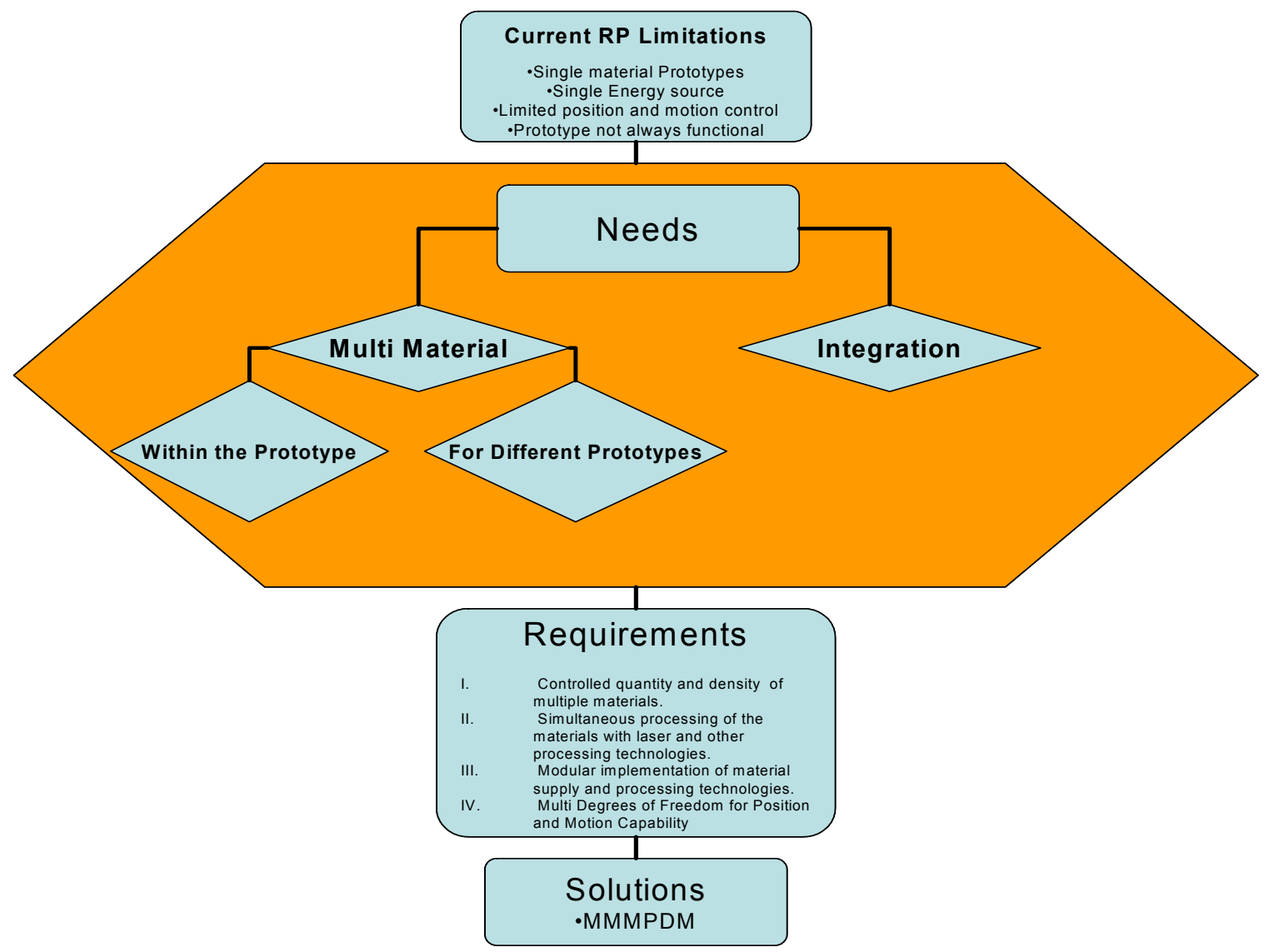

Figure 1: MMMPDM Design Process 
processing a wider range of materials in a more efficient way. Some processes are faster than others, while some are more efficient, therefore integration will benefit the entire manufacturing process in many different aspects such as cost, quality and reliability.

\section{Design Requirements}

In order to accomplish the previously described needs, the following design requirements need to be met:

\section{Controlled quantity and density of multiple materials.}

2. Simultaneous processing of the materials with laser and other processing technologies.

3. Modular implementation of material supply and processing technologies.

4. Multi degrees of freedom for position and motion capability

The initial design requirement can be accomplished by using different material feed systems driven by a control system. Control software needs to be implemented in order to manage material choice and feed rate. In this way, Locally Controlled Properties [13][14] and Functionally Graded Deposition [15][16][17] can also be achieved.

For the second design requirement, the system must be capable of using multiple power sources that can work either simultaneously or independently for the material processing. A laser beam can be used when accuracy is significant and an electric arc can be implemented to speed up the process. Flexibility in using more power sources is imperative when there is a need to process various materials. (i.e.: Some material can react differently to different wavelengths of laser radiations).

The design must also be modular; the capability of adding or removing material supplies and processes can increase the system's functionality and compactness.

The final design requirement is a critical factor in the manufacturing process. Some RP techniques have recently been used to fix parts of existing object such as turbine blades. Instead of replacing the entire rotor, the worn blades have been reconstructed utilizing laser deposition technology. Furthermore, if the surface of an object needs to be processed (Surface hardening or surface coating), more than three degrees of freedom are required in the position and motion control system.

\section{Functional structure}

The previous design requirements lead to the functional structure of the system. For our purposes, we can define a functional decomposition of the design process where three main inputs (Energy, Position and Material) are required by the system for generating the output (Material Deposition and Material Processing).

Our objective is to develop a system that is capable of building and processing 3D objects, and for this reason, deposition parameters are fundamental for the building process and material processing. The functional diagram can be seen in Figure 2.

The diagram shows that the two functions Energy and Position are fully connected to the system, meaning that they are essential for the system in order to output Material Processing. If we consider a process of heat treatment, there is solely a requirement for an energy source and a positioning system to process the specimen, therefore the input "Material" is not necessary for the process in order to work and therefore it is represented by a dashed line in Figure 2.

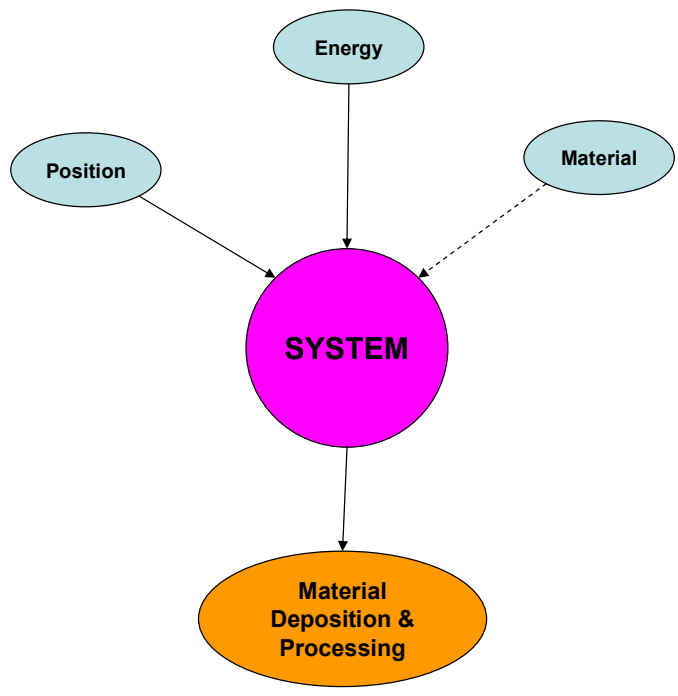

Figure 2: Functional Decomposition

\subsection{Energy}

The input Energy represents the power source needed to process the material. Currently different energy sources have been widely used in material processing and rapid prototyping (Laser, Electric Arc, Electron beam, Plasma gun). Depending on their characteristics or performance (such as speed, accuracy, interaction with materials, availability, costs, physical dimension, energy and delivery system), some are more suitable than others.

Table 1 compares the available energy sources with respect to characteristics and performances that are appropriate for our purposes. A simple weighting method $(+,-, 0)$ is implemented for the final design decision. 
Table 1: Available Energy Sources

\begin{tabular}{|c|c|c|c|c|}
\hline & Laser & $\begin{array}{c}\text { Electric } \\
\text { Arc }\end{array}$ & $\begin{array}{c}\text { Plasma } \\
\text { Gun }\end{array}$ & $\begin{array}{c}\text { Electron } \\
\text { Beam }\end{array}$ \\
\hline $\begin{array}{c}\text { Processing } \\
\text { Speed }\end{array}$ & 0 & + & + & 0 \\
\hline Accuracy & + & - & - & + \\
\hline $\begin{array}{c}\text { Interaction } \\
\text { with } \\
\text { Materials }\end{array}$ & - & + & + & + \\
\hline Cost & + & + & - & - \\
\hline $\begin{array}{c}\text { Delivery } \\
\text { System }\end{array}$ & + & 0 & + & - \\
\hline $\begin{array}{c}\text { Physical } \\
\text { Dimensions }\end{array}$ & + & + & 0 & - \\
\hline Availability & + & + & + & - \\
\hline $\begin{array}{c}\text { Ease of } \\
\text { Control }\end{array}$ & + & - & - & + \\
\hline + Signs & $\mathbf{6}$ & $\mathbf{5}$ & $\mathbf{4}$ & $\mathbf{3}$ \\
\hline - Signs & $\mathbf{1}$ & $\mathbf{2}$ & $\mathbf{3}$ & $\mathbf{4}$ \\
\hline 0 Signs & $\mathbf{1}$ & $\mathbf{1}$ & $\mathbf{1}$ & $\mathbf{1}$ \\
\hline Ranking & $\mathbf{1}$ & $\mathbf{2}$ & $\mathbf{3}$ & $\mathbf{4}$ \\
\hline
\end{tabular}

The table underlines that three out of four available technologies have gotten high scores in our priority scale; hence they are good candidates for our purposes. The electron beam does not fit in our priority list due to its predominantly negative scores. This technology remains relatively expensive in comparison to other technologies. Moreover, with the electron beam a vacuum chamber is required and the beam can not be flexibly transported such as a laser beams in fibre optics. Therefore the physical dimensions and delivery system are so far not suitable for our design purposes.

\subsection{Material}

Rapid prototyping technologies have been primarily classified by the material used, or more specifically, by the material physical composition. SLS (Selective Laser Sintering) uses metal, polymer or ceramic powder while FDM (Fused Deposition Modeling) requires polymers wires and SLA (Stereo Lithography) cures liquid polymers for creating objects. Different RP techniques, using the same material, can be differentiated from one another by means of the delivery technique of the specific material. A prototype can be built by spraying powder into the melting pool of a laser beam (LENS) or by scanning the surface of a powder bed (SLS).

Besides these techniques for material deposition we can also consider surface hardening processes using enriched gases such as Nitrogen and Carbon. A viable approach would be to spray those gases directly into the melting pool, caused by an energy source such as laser, when scanning the surface of a specimen to be processed.

For the reasons above we can consider the function Material in Figure 2 as composed by three sub functions:

1. Material variety (metals, polymers, ceramics),

2. Material physical composition (Solid Powder, Liquid, Wire, Gas)

3. Delivery systems.

From these functions we are able to create Table 2 indicating materials comparison and final decisions. From the scoring it is clear that powder (for material deposition) and gas (for surface processing) will be our first choice, but wires and liquid polymers need to be considered in order to increase the flexibility of the system.

Table 2: Material Choice

\begin{tabular}{|c|c|c|c|c|c|c|c|c|}
\hline & & & & & & & & \\
\hline & \multicolumn{2}{|c|}{ Metal } & \multicolumn{2}{|c|}{ Ceramic } & \multicolumn{3}{|c|}{ Polymer } & \multirow{2}{*}{ 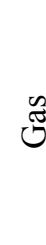 } \\
\hline & $\begin{array}{l}\dot{\vec{\theta}} \\
0 \\
0 \\
0\end{array}$ & $\stackrel{0}{3}$ & $\frac{\dot{\theta}}{0}$ & $\stackrel{0}{3}$ & $\begin{array}{l}-\overline{0} \\
\overline{0} \\
\vdots \\
0 \\
2\end{array}$ & $\stackrel{0}{3}$ & 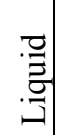 & \\
\hline Availability & + & + & + & - & + & + & 0 & + \\
\hline Costs & + & + & + & - & + & + & - & + \\
\hline $\begin{array}{l}\text { Delivery } \\
\text { accuracy }\end{array}$ & + & + & + & + & + & + & + & + \\
\hline $\begin{array}{l}\text { Ease of } \\
\text { delivery }\end{array}$ & + & 0 & + & 0 & + & 0 & + & + \\
\hline $\begin{array}{l}\text { Mixing } \\
\text { capability }\end{array}$ & + & - & + & - & + & - & 0 & + \\
\hline+ Signs & 5 & 3 & 5 & 1 & 5 & 3 & 2 & 5 \\
\hline - Signs & 0 & 1 & 0 & 3 & 0 & 1 & 1 & 0 \\
\hline 0 Signs & 0 & 1 & 0 & 0 & 0 & 1 & 2 & 0 \\
\hline Ranking & 1 & 2 & 1 & 4 & 1 & 2 & 3 & 1 \\
\hline
\end{tabular}

\subsection{Position}

The term position is a key function in our design decomposition. It represents the motion capability of 
the system for building or processing prototypes. The system would not have the ability to give any output if the input position as well as energy were missing.

Table 3: Positioning Systems

\begin{tabular}{|c|c|c|c|}
\hline & 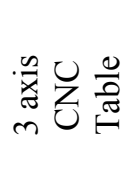 & 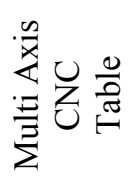 & 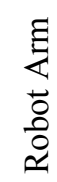 \\
\hline Accuracy & + & + & 0 \\
\hline Availability & + & + & 0 \\
\hline Position Efficiency & - & + & + \\
\hline Ease of Control & + & + & 0 \\
\hline Cost & + & - & - \\
\hline+ Signs & 4 & 4 & 1 \\
\hline - Signs & 1 & 1 & 1 \\
\hline 0 Signs & 0 & 0 & 3 \\
\hline Ranking & 1 & 1 & 2 \\
\hline
\end{tabular}

Table 3 lists few positioning mechanisms that have been ranked for our design decision. The table shows that the first two positioning systems have the same score and thereby should be given equal priority in the design decision. This is would be true if we were to consider a system that can build prototypes such as the existing RP technologies, but if we consider the capability of repairing or processing existing objects, as previously described, the position efficiency is a key factor. Thus the 3 axes table cannot be accepted due to his lack of flexibility.

\section{Principle solution}

It is now obvious that in order to meet the developed design requirements we need to design a machine that consists of the following major units:

1. Positioning control of the work piece in more than three axes (like a $\mathrm{CNC}$ machine).

2. Material supply unit.

3. Laser and alternative energy sources and associated instrumentation.

\section{Control system.}

The system we propose includes more than one material supply system, designed specifically for delivering powder or wire and liquids into the melting pool created by an energy source. Mixing chambers will be available for material mixing capability when simultaneous material processing is needed.

More than one energy source, such as a laser, electric arc, or plasma gun can be plugged into the system head. The particular design of the head allows all the energy sources to focus on the same processing point. In this way, both independent and simultaneous processes with a single or multiple power sources are achievable.

The system head is designed in such a way that the plugged power sources are able to slide along an ark shaped fork and rotate around $\mathrm{Z}$ axe, all the while keeping the focus on the same spot. The energy sources are connected to their power supply through flexible connections such as fibre optics or flexible hoses in order to guarantee motion freedom. A multi channel nozzle has the capability to feed liquid, powder and gas into the processing spot. The positioning system allows more that 3 degrees of freedom in order to build and process three dimensional prototypes.

The entire system is driven by a control hardware and software specifically designed for the proposed purpose. This principal solution is shown in Figure 3.

\section{Detailed Design:}

At this stage of the design process, the complete system shown in Figure 3 is still far from being realized. Our design choices are primarily derived by resource limitations and availability. The system we built has limited capabilities compared to the principal solution; however it is equipped for future upgrades. Our solution consists of the following units:

1. 150W Infrared Diode Laser coupled with fibre optic.

2. Two volumetric powder feeders

3. Carrier gas feeding system

4. 3 Axes CNC table

5. Customized Head

6. Control system and Software 


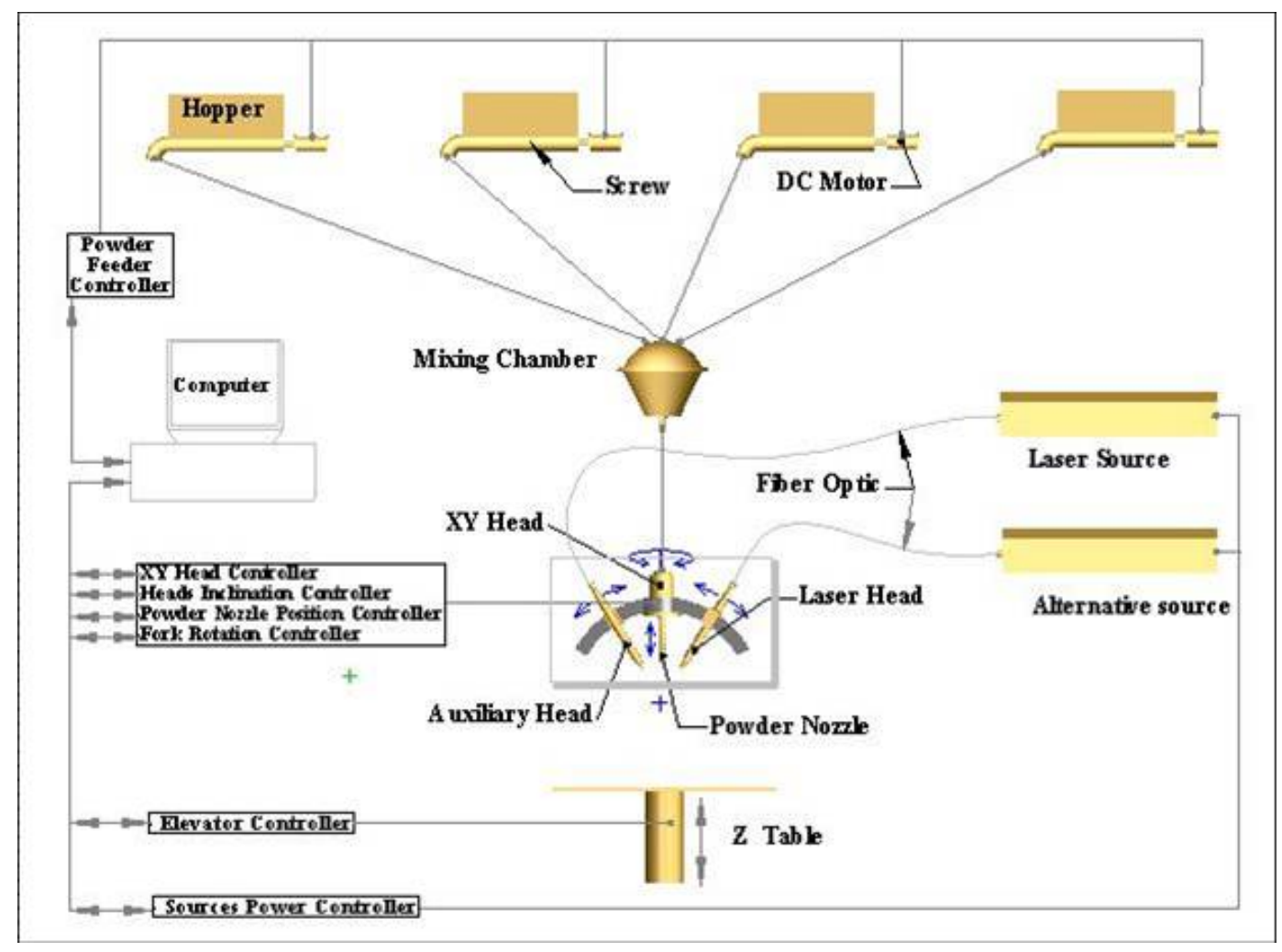

Figure 3: Principal Solution

There are many different Laser systems available in the market for our design. $\mathrm{CO}_{2}$ and $\mathrm{Nd}-$ Yag laser have been widely used for material deposition and processing, and lately Diode laser have been considered for their compact dimension and wavelength. When we deal with material processing we need to consider that material energy absorption is directly related to the energy wavelength. This is one of the main reasons of our choice is the diode laser. These kinds of laser systems are relatively inexpensive, compact and much more efficient in comparison to $\mathrm{CO}_{2}$ and $\mathrm{Nd}-\mathrm{Yag}$ in material processing due to their short wavelength $(940 \mathrm{~nm})$.

Figure 4 shows the optical absorption of various materials at different wavelength. From the graph it can be shown that below $1 \mu \mathrm{m}$ (Diode Laser wavelength) the absorption increases exponentially and consequently we can consider a $150 \mathrm{~W}$ diode laser as efficient as a $1000 \mathrm{~W} \mathrm{CO}_{2}$ for our purpose.

In regards to the material feeder, we have been constrained by resources. The two feeders are far from the optimal choice due to their feeding accuracy and pulsating feed rate. A fluidized bed powder feeder will definitely increase the accuracy and decrease the irregularity in the deposited line, making it a better candidate.

In order to reduce the pulsating phenomena in our feeders, we chose to enclose the feeders in Argonpressurized acrylic boxes. With this configuration we have achieved three benefits:

1. Reduction of the feed pulsations

2. Mixing capability of the two materials stored in the feeders. The gas during its flow to the melting pool carries the powder particles through a mixing chamber. In this way the two materials can be dynamically mixed before reaching the melting pool.

3. The melting zone is consequentially shielded by the inert carrier gas avoiding oxidation due to the oxygen content in the surrounding air.

For the positioning system we opted for a 3 axes CNC table available in the department, although limitations in the system will remain, as previously described in the explanation of Table 3. 


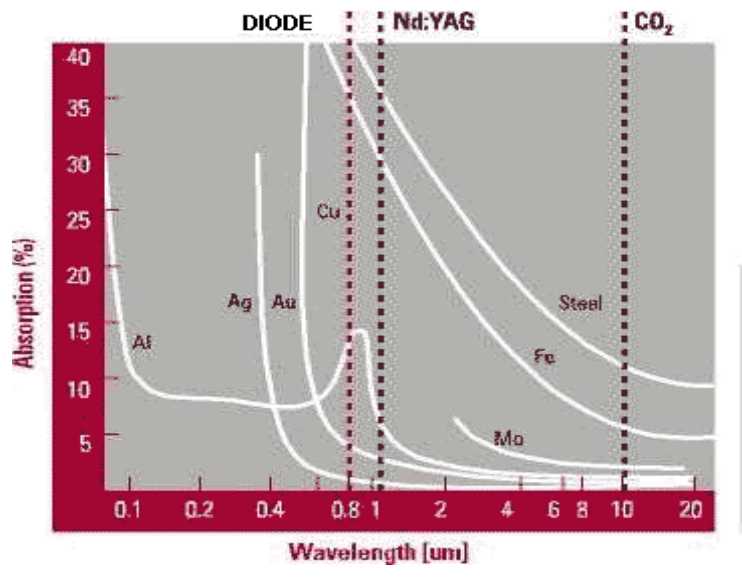

Figure 4: Lasers Comparison [18]

The laser optics and the feed nozzle are plugged onto a head custom designed based on physical constraints and design requirements. The head has been designed to fit on the existing $\mathrm{Z}$ axe of a $\mathrm{CNC}$ table after removing the spindle. The laser optic slides on an arc shaped fork for approximately 30 degrees, while at the same time can rotate around the main pin that connects the fork to the fork holder, all the while keeping the focus on the same spot. The fork holder is connected to the $\mathrm{Z}$ axe of the $\mathrm{CNC}$ table in place of the existing spindle. In this way two more degrees of freedom have been added to system. The solid model of the head can be shown in Figure 5.

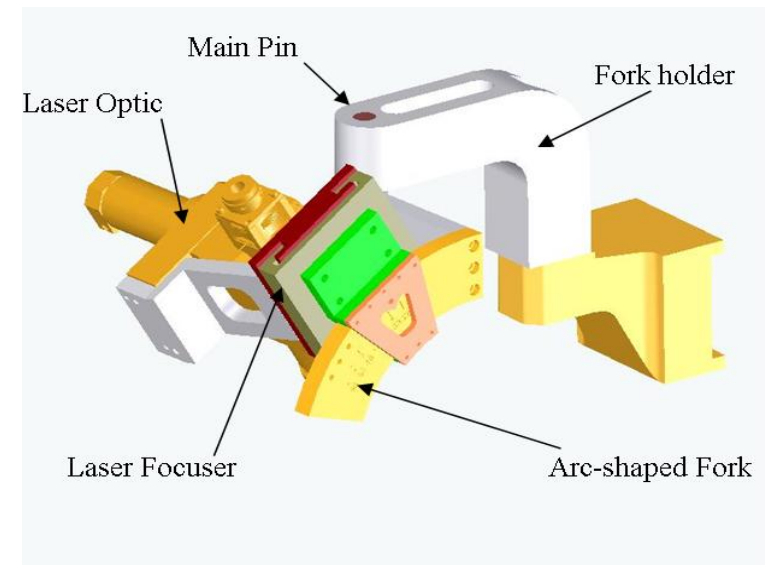

Figure 5: Head Design
At this stage of development, a National Instrument control board and LabView platform have been adopted to control the powder feeder and the laser power supply. The developed software is capable of monitoring and controlling the laser functions and it can also dynamically control the powder feed rate simultaneously, allowing a fine adjustment and mixing capability of both the materials used.

\section{Conclusion and future work}

We proposed a system that overcomes the most common limitation of the existing rapid prototyping technologies. The final system will be capable of changing material supply and energy source on demand for building and processing a variety of objects. The system can be considered a unique machining center in terms of material deposition and processing and it will be capable of integrating the most common RP process in one single machine. At this stage of development, our machine can easily integrate the use of more than one material supply and it is ready for a second power source. Hardware, control software and building sample are shown in Figure 6. Further investigation will be made to improve the complete system.

Although the system proposed has some limitations due to design constraints previously mentioned, it has demonstrated that it meets most of the design needs. The system has been tested by building different samples. Thus far simple thin walls have been created with two materials such as copper and iron. The materials have been processed separately and simultaneously in order to create single material and functionally graded walls. The modular implementation has been undertaken exclusively on the material supply. Feeding modules can easily be added and removed from the system. The machine has limited dimensional control because of its poor positioning system, but future work will address positioning system improvement and add a second energy source. The control software will be upgraded in order to control the second energy source and more than two materials. 


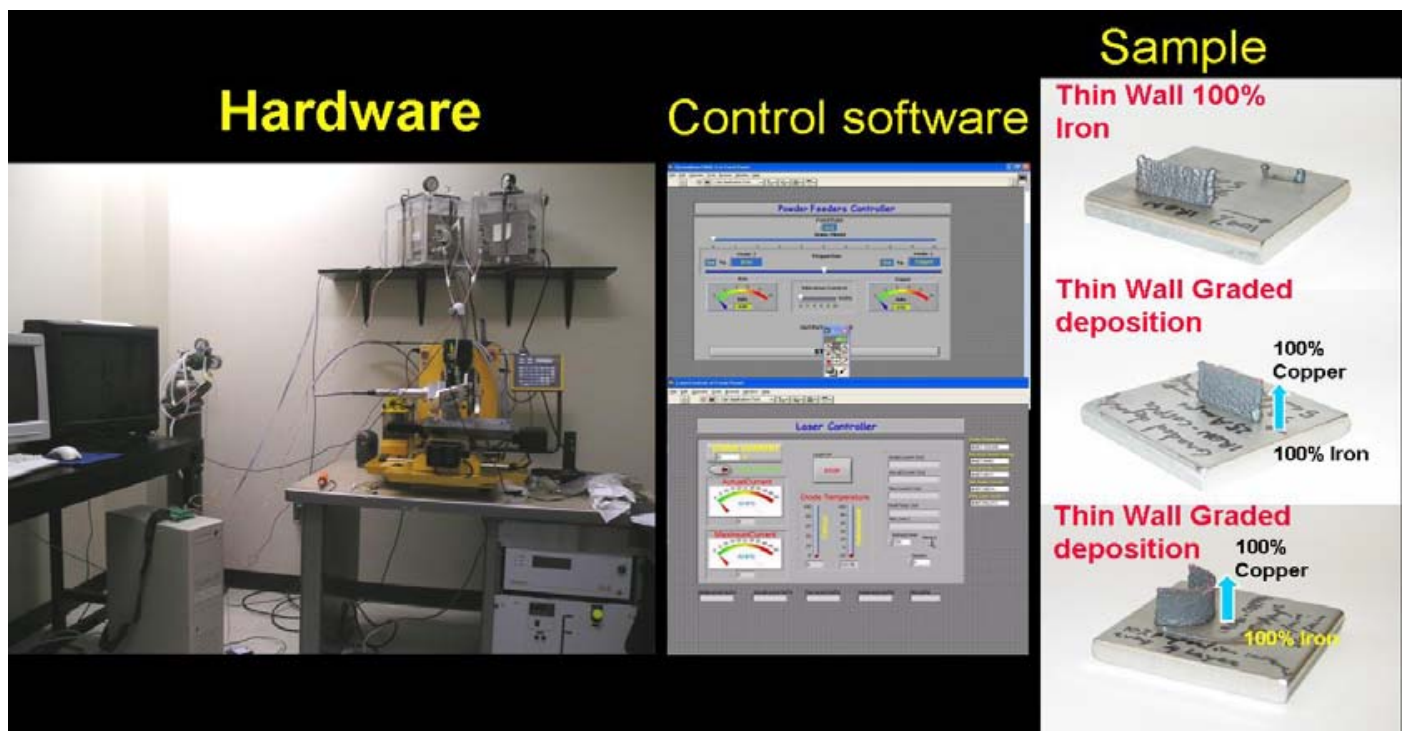

Figure 6: System and Samples

\section{Acknowledgements}

We would like to thank Mike Johnson and Dave Gange for their assistance in machining the system's components and software development. Financial support provided by Natural Sciences and Engineering Research Council of Canada through a Discovery Grant RGP 192173 is greatly appreciated.

\section{References}

[1] Onuh, S.O. (Univ of Liverpool), Yusuf, Y.Y. "Rapid prototyping technology: Applications and benefits for rapid product development", Journal of Intelligent Manufacturing, v 10, n 3, 1999, p 301-311

[2] Kulkarni, P. (Univ of Michigan); Dutta, D., "Deposition strategies and resulting part stiffnesses in fused deposition modeling", Journal of Manufacturing Science and Engineering, Transactions of the ASME, v 121, n 1, Feb, 1999, p 93-103

[3] Sun, Q. (Department of Chemical Engineering, University of Calgary); Rizvi, G.M.; Giuliani, V.; Bellehumeur, C.T.; Gu, P. "Experimental study and modeling of bond formation between ABS filaments in the FDM process", Annual Technical Conference ANTEC, Conference Proceedings, v 1, ANTEC 2004 Annual Technical Conference proceedings, Volume 1: Processing, 2004, p 1158-1162

[4] Hull, Charles (3D Systems Inc) "StereoLithography: Plastic prototypes from CAD data without tooling", Modern Casting, v 78, n 8, Aug, 1988, p38

[5] Furukawa, Susumu; Itoh, Makoto; Yamada, Susumu; Hagihara, Shigeru Source: Nippon Kikai Gakkai
Ronbunshu, "CAD/CAM system for free-form shape design", C Hen/Transactions of the Japan Society of Mechanical Engineers, Part C, v 56, n 526, Jun, 1990, p 1632-1637 Language: Japanese

[6] Anon, "Affordable prototypes are made without tooling”, Modern Plastics, v 66, n 3, Mar, 1989, p 8485

[7] Bourell, D.L. (Univ of Texas, Austin); Crawford, R.H.; Marcus, H.L.; Beaman, J.J.; Barlow, J.W. "Selective Laser Sintering of metals", Manufacturing Science and Engineering, American Society of Mechanical Engineers, Production Engineering Division (Publication) PED, v 68-2, , 1994, p 519-528

[8] Berzins, M. (Univ of Leeds); Childs, T.H.C.; Ryder, G.R. "Selective laser sintering of polycarbonate", CIRP Annals - Manufacturing Technology, v 45, n 1, 1996, p 187-190

[9] Goode, Elizabeth (3D Systems), "Selective laser system and materials sintering", Advanced Materials and Processes, v 161, n 1, January, 2003, p 66-67

[10] Hedges, M. (Neotech Services MTP), "Laser engineered net shaping [trademark] - Technology, applications, and opportunities in fluid machinery", IMechE Event Publications, $v 2004$ 1, Second International Symposium on Advanced Materials for Fluid Machinery, 2004, p 133-144

[11] Griffith, Michelle L. (Sandia Natl Lab); Keicher, David L.; Romero, J. Tony; Smugeresky, John E.; Atwood, Clint L.; Harwell, Lane D.; Greene, Don L. "Laser Engineered Net Shaping (LENSTM) for the fabrication of metallic components", Advanced Materials: Development, Characterization Processing, and Mechanical Behavior ,American Society of Mechanical Engineers, Materials Division (Publication) MD, v 74, , 1996, p 175-176 
[12] Steen, W. M. (Imperial Coll, London, Engl), "LASER SURFACE CLADDING", Applied Sciences, NATO

ASI Series, Series E:, n 115, 1986, p 369-387

[13] Gu, P. (Department of Mechanical Engineering, University of Calgary); Li, L., "Fabrication of biomedical prototypes with locally controlled properties using FDM", CIRP Annals - Manufacturing Technology, v 51, n 1, 2002, p 181-184

[14] Unocic, R.R. (Dept. of Materials Science and Eng., Lehigh University); DuPont, J.N., "Composition control in the direct laser-deposition process" Metallurgical and Materials Transactions B: Process Metallurgy and Materials Processing Science, v 34, n 4, August, 2003, p 439-445.

[15] Jackson, T.R. (Massachusetts Inst of Technology); Liu, H.; Patrikalakis, N.M.; Sachs, E.M.; Cima, M.J., "Modeling and designing functionally graded material components for fabrication with local composition control", Materials and Design, v 20, n 2-3, Jun, 1999, p 63-75

[16] Domack, M.S. (NASA Langley Research Center); Baughman, J.M.,'Development of nickel-titanium graded composition components", Rapid Prototyping Journal, v 11, n 1, 2005, p 41-51

[17] Collins, P.C. (Dept. of Materials Science/Eng., The Ohio State University); Banerjee, R.; Banerjee, S.; Fraser, H.L., "Laser deposition of compositionally graded titanium-vanadium and titanium-molybdenum alloys", Materials Science and Engineering A, v 352, n 1-2, Jul 15, 2003, p 118-128

[18] Nuvonyx Inc.. www.nuvonyx.com/overview 